\title{
PELATIHAN E-LEARNING BERBASIS MOODLE UNTUK DOSEN-DOSEN UNIVERSITAS ISLAM KALIMANTAN MAB BANJARMASIN
}

\author{
Hamdan Husein Batubara \\ Pendidikan Guru Madrasah Ibtidaiyah, Universitas Islam Kalimantan MAB Banjarmasin \\ huseinbatubara@gmail.com
}

\begin{abstract}
ABSTRAK
Abstrak: Penggunaan e-learning diyakini dapat mengatasi keterbatasan perkuliahan di kelas dan menyediakan layanan belajar yang dapat diakses darimana saja dan kapan saja. Kebijakan penggunaan e-learning di Universitas Islam Kalimantan MAB Banjarmasin masih tergolong baru dan sebagian besar dosen belum mengerti cara menggunakannya. Oleh karena itu, kegiatan pelatihan ini diharapkan dapat meningkatkan keterampilan dosen dalam menggunakan e-learning. Pelatihan ini dilaksanakan selama dua hari di Universitas Islam Kalimantan MAB Banjarmasin dengan melibatkan dosen-dosen dari perwakilan program studi. Kegiatan dilaksanakan dalam bentuk simulasi, latihan, dan pemecahan masalah. Materi pelatihan adalah pedoman penggunaan e-learning berbasis Moodle untuk dosen, yang terdiri dari pengaturan mata kuliah, penambahan sumber belajar, membuat grup, memantau progress belajar mahasiswa, dan penggunaan fitur forum, chatting, penugasan, kuis, dan laporan nilai. Kegiatan pelatihan dapat dikatakan berhasil berdasarkan kemampuan peserta dalam memperagakan materi dan dibuktikan dengan hasil karya mereka pada laman e-learning. Peserta merasa pelatihan ini penting karena dapat meningkatkan keterampilan mereka dalam mengelola pembelajaran melalui e-learning.
\end{abstract}

Kata Kunci: Pelatihan, E-Learning, Moodle, Perguruan Tinggi

\begin{abstract}
The use of e-learning is believed to overcome the limitations of teaching in the classroom and provide learning services that can be accessed from anywhere and anytime. The policy of using e-learning at the Islamic University of Kalimantan $M A B$ Banjarmasin is still relatively new and most of the lecturers do not understand how to use it. Therefore, this training is expected to improve lecturers' skills in using $e^{-}$ learning. The training was held for two days at the Islamic University of Kalimantan $M A B$ Banjarmasin involving lecturers from representatives of the department. Activities are carried out in the form of simulations, exercises, and problem solving. Training materials are Moodle-based e-learning guidelines for lecturers, consisting of setting course, adding learning resources, creating groups, monitoring student progress, and using forum features, chats, assignments, quizzes and grader report. Training activities can be said to be successful based on participants' ability to demonstrate the material and be proven by their work on the e-learning page. Participants feel this training is important because it can improve their skills in managing learning through e-learning.
\end{abstract}

Keywords: Training, E-Learning, Moodle, College

Riwayat Artikel: Diterima: 13-01-2018, Disetujui: 29-01-2018 


\section{A. PENDAHULUAN}

\section{Analisis Situasi}

Pemanfaatan teknologi informasi dan komunikasi dalam pembelajaran telah diyakini mampu meningkatkan kualitas pelayanan akademik dan mengatasi keterbatasan pembelajaran di kelas. Menyadari akan hal itu, pimpinan Universitas Islam Kalimantan MAB Banjarmasin untuk mengembangkan sistem e-learning menggunakan software Modular Object-Oriented Dynamic Learning Environment (Moodle). E-learning tersebut dipasang pada server universitas dan semua civitas akademika dapat mengaksesnya menggunakan akun sistem informasi akademik.

E-Learning sebagai perangkat e-leaktronik modern memerlukan keterampilan khusus dalam penggunaannya. Dosen-dosen Universitas Islam Kalimantan MAB Banjarmasin sebenarnya sejak lama telah terbiasa dengan penggunaan teknologi informasi dalam pengelolaan pembelajaran. Namun penggunaannya belum tersistem dengan baik dan mereka menggunakannya secara sendiri-sendiri sesuai dengan kemampuannya. Di antara aplikasi TIK yang digunakan para dosen dalam mengajar adalah: email, blog, media sosial, Youtube, dan Edmodo.

Kebijakan penggunaan e-learning berbasis Moodle yang masih baru dan belum adanya petunjuk dan pelatihan tentang cara menggunakan e-learning tersebut membuat para dosen belum memanfaatkannya untuk mendukung kegiatan pembelajaran. Hasil wawancara penulis dengan dosen-dosen dan pimpinan menunjukkan bahwa mereka memerlukan kegiatan pelatihan tentang penggunaan $e^{-}$ learning berbasis Moodle.

Pelatihan e-learning berbasis Moodle ini ditujukan untuk memberikan keterampilan kepada para dosen tentang cara menggunakan e-learning. Di antara fitur-fitur e-learning yang harus dikuasai oleh dosen adalah: 1) mengelola halaman mata kuliah, 2) mengatur peserta kuliah dan metode pendaftarannya, 3) mengisi mata kuliah dengan berbagai jenis konten pembelajaran, 4) mengelola grup mahasiswa sesuai kelasnya, 5) menggunakan fitur penugasan dan kuis online, 6) membuat dan menyimpan soal pada bank soal, 7) menggunakan chatting dan forum, 6) menggunakan ruang penyimpanan data pribadi, 7) menggunakan fitur pemantau progres belajar mahasiswa, 8) menggunakan fitur web conference, feedback, dan penilaian. 


\section{Permasalahan Mitra}

Berdasarkan uraian di atas dapat dirumuskan permasalahan mitra sebagai berikut.

a. Konten e-learning Universitas Islam Kalimantan MAB masih sedikit dan hal tersebut menunjukkan bahwa para dosen belum memanfaatkannya dengan baik

b. Sebagian besar dosen mengakui belum memahami cara penggunaan fitur-fitur e-learning. Hal tersebut dikarenakan belum tersedianya pelatihan e-learning bagi dosen belum tersedianya buku petunjuk penggunaan e-learning.

c. Investasi Universitas terhadap server e-learning akan mengalami kerugian jika tidak dimanfaatkan dengan baik.

d. E-learning berpotensi untuk membantu dosen dan mahasiswa dalam meningkatkan kualitas pembelajaran di kelas.

\section{B. KAJIAN PUSTAKA}

\section{Pengertian E-learning}

E-learning merupakan singkatan dari electronic learning yang berarti pembelajaran elektronik atau pembelajaran yang menggunakan jasa/ bantuan perangkat elektronik (Batubara, 2017). Jaya Kumar C. Koran dalam Yazdi mendefinisikan e-learning sebagai kegiatan pembelajaran yang menggunakan rangkaian elektronik (LAN, WAN, atau internet) untuk menyampaikan isi pembelajaran, interaksi, atau bimbingan, dan untuk memperoleh sumber belajar yang sesuai dengan kebutuhannya (Yazdi, 2012).

Secara umum terdapat dua persepsi tentang pengertian $e^{-}$ learning, yaitu: Electronic based e-learning dan Internet based $e^{-}$ learning. Electronic based adalah kegiatan pembelajaran yang diselenggarakan menggunakan bantuan media elektronik seperti internet, TV, CD-ROM, radio, dan lain-lain. Dalam pengertian ini, internet hanya salah satu bagian dari e-learning. Adapun Internet Based berarti bahwa kegiatan pembelajaran tertuju pada penggunaaan teknologi internet sebagai sarana dalam belajar (Ridwan 2011).

Dengan demikian, e-learning adalah pembelajaran yang pelaksanaannya didukung oleh bantuan perangkat elektronik, seperti komputer, smartphone, audio, videotape, atau jaringan. Penggunaan teknologi komputer dan jaringan pada e-learning menjadi keunggulan sekaligus tantangan bagi penyelenggara e-learning. Oleh karena itu, penyelenggaraannya memerlukan kesiapan kompetensi pengguna dalam mengoperasikan software e-learning, mengkonversi bahan cetak menjadi bahan digital atau media interaktif, dan didukung oleh perangkat computer, listrik, dan jaringan internet yang memadai. 


\section{Manfaat E-learning}

Hasil penelitian Marikar \& Jayarathne mengungkapkan bahwa implementasi e-learning berbasis Moodle di General Sir John Kotelawela Defence University Srilanka mendapat respon positif dan dapat meningkat prestasi peserta didik (Marikar, 2016). Hasil penelitian Martín-Blas juga mengungkapkan bahwa penggunaan e-learning sebagai ruang virtual dapat memperkuat pengetahuan dan kemampuan peserta didik (Martín-Blas, 2009).

Adapun di antara manfaat penerapan e-learning bagi peserta didik, pendidik, dan budaya belajar adalah sebagai berikut.

a. Peserta didik

1) Menyediakan materi pembelajaran yang terprogram kepada peserta didik untuk belajar di luar kelas

2) Menumbuhkan percaya diri pada peserta didik dalam berkomunikasi secara santun dan beretika saat berkomunikasi dengan orang yang tidak tampak fisiknya

3) Menyediakan kesempatan belajar kepada peserta didik yang trauma dengan sekolah, dirawat di rumah sakit, putus sekolah tetapi berminat melanjutkan pendidikan, dan peserta didik yang berada di berbagai daerah atau bahkan yang berada di luar negeri

4) Memberikan kesempatan belajar kepada peserta didik yang berada jauh dari lembaga pendidikan, memiliki kesibukan, atau tidak tertampung di sekolah konvensional.

b. Pendidik

1) Memudahkan pendidik dalam melakukan pemutakhiran bahanbahan belajar yang menjadi tanggung jawabnya

2) Membantu pendidik dalam mengontrol kegiatan belajar peserta didik, seperti: kapan peserta didiknya belajar, topik apa yang dipelajari, berapa lama suatu topik dipelajari, serta berapa kali topik tertentu dipelajari ulang

3) Membantu pendidik dalam mengecek kegiatan peserta didik dalam mengerjakan soal-soal latihan setelah mempelajari topik tertentu

4) Membantu pendidik dalam memeriksa jawaban peserta didik dan memberitahukan hasilnya kepada peserta didik.

c. Budaya belajar

1) Memungkinkan seseorang maju unggul atas prakarsa sendiri untuk tujuan sendiri dengan cara berkomunikasi dengan berbagai pihak menggunakan media internet

2) Menumbuhkan sikap demokratis karena belajar menggunakan $e^{-}$ learning tidak memandang berbagai simbol status yang melekat pada diri seseorang 
3) Menumbuhkembangkan kebiasaan belajar mandiri bagi peserta didik melalui fasilitas konten belajar yang lengkap, dan fitur komunikasi melalui forum dan chat (Darmawan, 2016).

Dari beberapa manfaat di atas dapat diketahui bahwa manfaat dan keunggulan e-learning terletak pada keunggulan jaringan internet, software yang digunakan, kemampuan penyelenggara, dan kelengkapan konten pembelajaran e-learning. Tanpa keempat hal tersebut maka manfaat e-learning tidak akan tercapai dengan baik.

\section{Model Pembelajaran Berbasis E-Learning}

Pengembangan pembelajaran berbasis e-learning perlu dirancang secara cermat agar sesuai dengan tujuan yang diharapkan. Kemenristek Dikti (2016) membagi model pembelajaran e-learning ditinjau dari porsi pemanfaatan Teknologi Informasi dan Komunikasi kepada tiga bagian, yaitu:

\section{a. Web Enhanced e-learning}

Model pembelajaran ini dilaksanakan dengan tatap muka dan diperkaya dengan teknologi internet sebagai sumber belajar tambahan. Teknologi internet tersebut dapat berupa Learning Management System, website, blog, atau jejaring sosial untuk menunjang kualitas pembelajaran yang dilakukan di kelas. Fungsi internet adalah untuk memberikan pengayaan dan komunikasi antara peserta didik dengan pengajar, sesama peserta didik, anggota kelompok, atau peserta didik dengan narasumber lain. Oleh karena itu peran pengajar dalam hal ini dituntut untuk menguasai teknik mencari informasi di internet, membimbing pelajar mencari dan menemukan situs-situs yang relevan dengan bahan pembelajaran, menyajikan materi melalui website dengan menarik dan diminati, melayani bimbingan dan komunikasi melalui internet, dan kecakapan lain yang diperlukan.

\section{b. Blended or Hybrid learning}

Model pembelajaran ini mengkombinasikan pembelajaran online dan tatap muka. Sebagian materi disampaikan melalui internet dan sebagian lagi melalui tatap muka. Tujuannya adalah agar keterbatasan yang terdapat pada pembelajaran tatap muka dapat diatasi dengan pembelajaran melalui e-learning dan kesulitan pelajar dalam belajar melalui e-learning dapat diatasi melalui pembelajaran tatap muka. Dalam model ini pengajar bisa memberikan petunjuk pada pelajar untuk mempelajari materi pelajaran melalui website yang telah dibuatnya. Pelajar juga diberikan arahan untuk mencari sumber lain dari situssitus yang relevan. Dalam tatap muka, peserta didik dan pengajar lebih banyak diskusi tentang temuan materi yang telah dipelajari melalui $e^{-}$ learning. 


\section{c. Fully Online}

Model Pembelajaran ini sebagian besar atau seluruhnya dilaksanakan secara online melalui sistem e-learning. Peserta didik dan pengajar sepenuhnya terpisah dan tidak diperlukan adanya tatap muka. Model pembelajaran ini disebut juga dengan web based learning dan distance learning. Seluruh bahan ajar, diskusi, penugasan, latihan, ujian, dan kegiatan pembelajaran lainnya sepenuhnya disampaikan melalui $e^{-}$ learning atau m-learning.

\section{METODE PELAKSANAAN}

\section{a. Langkah-Langkah Kegiatan}

Kegiatan Program Pengabdian Pada Masyarakat dilaksanakan selama dua hari dengan metode yang terpadu antara demonstrasi, latihan, dan tanya jawab.

a. Demonstrasi

Instruktur memperagakan atau menunjukkan langkah-langkah penggunaan berbagai fitur yang tersedia dalam e-learning secara sistematis dan mengacu pada silabus pelatihan.

b. Latihan

Kegiatan latihan dilaksanakan oleh peserta pelatihan dengan mengikuti demonstrasi yang diberikan instruktur atau langkahlangkah yang dijelaskan pada modul pelatihan e-learning.

c. Tanya Jawab

Pada proses pelatihan berlangsung, peserta diberikan kesempatan seluas-luasnya untuk menanyakan berbagai kesulitan yang dihadapinya saat menggunakan e-learning.

Adapun pembagian materi dalam pelaksanaan Kegiatan Program Pengabdian Kepada Masyarakat adalah sebagai berikut.

d. Hari pertama, pelaksana kegiatan menyampaikan tujuan dan silabus pelatihan e-learning. Kemudian dilanjutkan dengan demosntrasi dan latihan pengaturan halaman mata kuliah, sesi pembelajaran, pendaftaran peserta kuliah, pengelompokan mahasiswa, pemantauan progres belajar mahasiswa, pengisian konten mata kuliah dengan modul page, file, folder, book, label, url, dan IMS Content Package, penggunaan fitur forum dan chatting.

e. Hari kedua, peserta dilatih untuk mampu menggunakan fitur pemberian tugas kepada mahasiswa, yang terdiri dari pengaturan, pemeriksaan, dan penilaian tugas. Kemudian peserta dilatih untuk mampu membuat dan menyimpan soal pada bank soal, mengatur penyelenggaraan kuis online, mengelola soal kuis, dan mengatur sistem penilain dalam e-learning. 


\section{b. Khalayak Sasaran}

Kegiatan pengabdian pada masyarakat ini ditujukan pada Dosendosen Universitas Islam Kalimantan MAB Banjarmasin, Jl. Adhyaksa No. 2, Kayu Tangi, Banjarmasin. Jumlah dosen yang mengikuti pelatihan e-learning ini berjumlah 20 orang.

\section{HASIL DAN PEMBAHASAN}

\section{Proses Pelaksanaan Pelatihan}

Hasil kegiatan pelatihan e-learning berbasis Moodle untuk dosendosen Universitas Islam Kalimantan terlaksana sesuai dengan rencana jadwal yang telah disusun telah dihadiri oleh 20 orang sebagai peserta pelatihan. Adapun materi-materi pokok yang dijelaskan pada kegiatan pelatihan tersebut adalah sebagai berikut:

a. Metode Pendaftaran pada situs e-learning

b. Membuat mata pelajaran baru dan pengaturan mata kuliah

c. Mengelola Metode Pendaftaran mata kuliah

d. Mengelola peserta mata kuliah

e. Mengisi konten mata kuliah dengan beragam jenis materi

f. Mengelola forum dan chatting

g. Membuat kegiatan penugasan

h. Mengelola bank soal

i. Membuat kegiatan kuis

j. Mengelola nilai

Semua materi tersebut dibahas dalam bentuk demonstrasi, latihan langsung dan tanya-jawab. Kegiatan pelatihan ini sengaja tidak dimulai dari penyajian teori untuk menghemat waktu pelatihan. Meskipun demikian, pelaksana tetap menghimbau peserta untuk membaca teori tentang e-learning pada buku modul pelatihan.

Adapun beberapa perlengkapan yang digunakan dalam kegiatan pelatihan ini adalah sebagai berikut.

a. Laboratorium komputer universitas yang terhubung ke internet. Peserta pelatihan juga diperkenankan untuk membawa dan mnggunakan laptop pribadi pada saat pelatihan berlangsung

b. Modul Pelatihan E-Learning (disiapkan oleh pelaksana)

c. Konten Pembelajaran elektronik (dibawa oleh peserta)

Penyajian materi dan jawaban terhadap pertanyaan peserta didemonstrasikan pada layar proyektor agar semua peserta dapat menyaksikannya. Pada saat kegiatan pelatihan berlangsung, instruktur menganjurkan agar peserta yang lebih cepat memahami materi membantu peserta yang lambat agar seluruh materi pelatihan dapat diperagan dan dimengerti oleh semua peserta. 
Adapun beberapa pertanyaan yang dilontarkan peserta saat kegiatan pelatihan berlangsung adalah sebagai berikut:

a. Barsihanor

1) Bagaimana cara mengubah pengaturan kuis?

2) Bagaimana cara mengubah nilai kuis mahasiswa?

b. Galuh Nashrullah Kartika MR

1) Apakah file yang diunggah ke e-learning akan bisa diakses orang lain yang bukan mahasiswa?

2) Bagaimana cara menambahkan video dari Youtube ke halaman mata kuliah e-learning?

c. M. Rifki Hidayat

Bagaimana cara mengaktifkan fitur pemantauan aktivitas mahasiswa pada e-learning?

Semua pertanyaan tersebut telah dijelaskan secara bertahap sambil memperagakannya di hadapan semua peserta pelatihan sehingga semua peserta merasa puas dengan pelatihaan yang telah diberikan. Selama kegiatan, peserta pelatihan tampak aktif dan sangat tertarik dalam menirukan langkah-langkah yang didemonstrasikan instruktur, bertanya, dan meminta bantuan teman yang lebih cepat terampil.

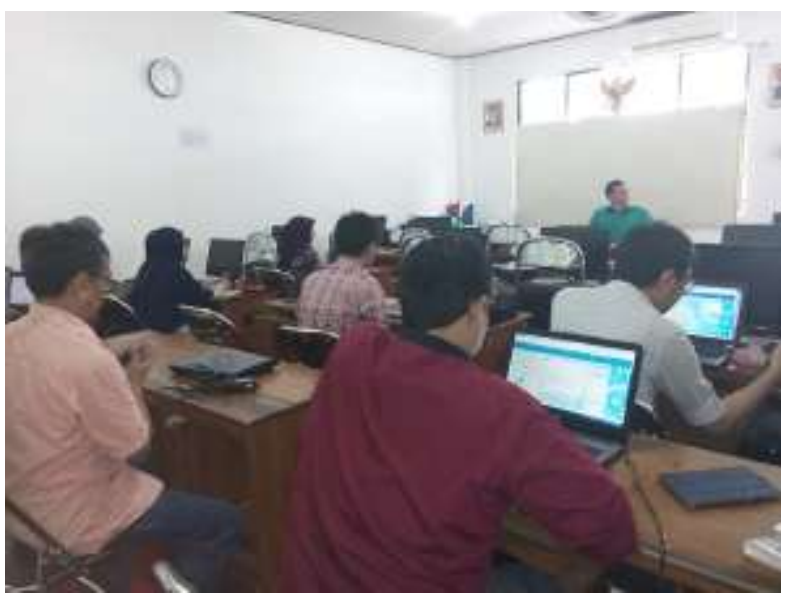

Gambar 1. Peserta pelatihan e-learning

\section{Kendala Pelaksanaan Pelatihan}

Pelatihan e-learning berbasis Moodle ini dilaksanakan dalam rangkaian kegiatan pengabdian pada masyarakat. Dalam hal ini, pengabdian dilaksanakan di ruang Laboratorium Komputer Universitas Islam Kalimantan MAB Banjarmasin. Adapun beberapa kendala pelatihan ini dapat dirincikan sebagai berikut.

a. Waktu pelaksanaan terlalu singkat untuk materi e-learning yang cukup padat sehingga hasilnya masih kurang maksimal. Pelaksana mengatasinya dengan menyajikan materi pelatihan secara sistematis dan dengan bantuan gambar pada sebuah buku modul. 
b. Sebagian dosen kurang disiplin dan dosen yang memiliki jabatan struktural terkadang meninggalkan ruangan sehingga penyampaian materi kurang efektif. Untuk mengatasi hal ini, pelaksana harus memilih waktu yang tepat untuk melaksanakan pelatihan e-learning dan meminta pimpinan untuk meliburkan peserta selama kegiatan pelatihan berlangsung.

c. Pengetahuan awal sebagian dosen tentang website masih rendah sehingga instruktur harus menjelaskan dari awal dengan pelanpelan. Sedangkan sebagian dosen lain cukup cepat dalam memahami materi, Pelaksana mengatasinya dengan meminta para peserta yang cepat tanggap untuk membantu peserta yang lambat agar semua materi dapat disampaikan dengan efesien.

d. Koneksi internet kurang stabil pada siang hari karena civitas akademik banyak yang menggunakan. Pada pelatihan berikutnya, pelaksana harus mempersiapkan modem tambahan untuk mengantisipasi jika sewaktu-waktu kondisi jaringan down atau meminta operator jaringan kampus untuk memprioritaskan jaringan ke saluran tertentu.

\section{E. SIMPULAN DAN SARAN}

Berdasarkan hasil kegiatan pengabdian pada masyarakat yang berupa pelatihan e-learning berbasis Moodle untuk dosen-dosen di lingkungan Universitas Islam Kalimantan MAB Banjarmasin maka dapat disimpulkan sebagai berikut.

a. Pelatihan e-learning berbasis Moodle dapat dilaksanakan dengan sukses, lancar sesuai dengan rencana.

b. Kegiatan pelatihan ini memberikan pengetahuan dan keterampilan kepada para dosen tentang cara mengelola pembelajaran menggunakan e-learning Moodle.

c. Tingkat pemahaman peserta kegiatan tengan penggunaan e-learning berbasis Moodle meningkat setelah diadakan pelatihan ini.

d. Kegiatan pelatihan e-learning memerlukan perencanaan yang cermat dan kerjasama dengan pimpinan universitas

Kegiatan pelatihan e-learning perlu dilanjutkan secara bertahap kepada operator e-learning dan dosen-dosen lain yang belum memiliki kesempatan dalam mengikuti pelatihan e-learning. Kegiatan pelatihan e-learning ini juga perlu didukung oleh kegiatan pelatihan yang mengangkat topik tentang cara membuat bahan ajar berbasis TIK (membatik) dengan menggunakan berbagai software. Seperti Lectora Inspire, Quiz Creator, Camtasia, dan lainnya. Pelatihan tersebut juga harus dilaksanakan dengan persiapan dan perencanaan yang lebih cermat dan bekerjasama dengan lembaga terkait. 


\section{DAFTAR RUJUKAN}

Batubara, H. H. (2017). Pengembangan Situs E-Learning dengan Moodle Versi 3.1 sebagai Media Pembelajaran pada Program Studi Pendidikan Guru Madrasah Ibtidaiyah. Al-Bidayah: Jurnal Pendidikan Dasar Islam, 9 (1), 1 10. doi:10.14421/jpdi.2017.0901-01

Darmawan, D. (2016). Pengembangan E-learning: Teori dan Desain. Bandung: PT. Remaja Rosdakarya.

Kementerian Riset, Teknologi dan Pendidikan Tinggi, Kebijakan Pendidikan Jarak Jauh dan E-Learning di Indonesia, Kemenristek Dikti, Jakarta, 2016.

Marikar, F. M. (2016). Effectiveness of MOODLE in Education System in Sri Lankan University. International Journal of Modern Education and Computer Science, 8 (2), 54.

Martín-Blas, T. \&.-F. (2009). The role of new technologies in the learning process: Moodle as a teaching tool in Physics. Computers \& Education, 52(1), 35-44.

Ridwan, M. (2011). Pengaruh Pembelajaran Berbasis E-Learning Terhadap Prestasi Belajar Siswa Kelas XII Akuntansi Mata Pelajaran Fiqih Di Smk Ypm 3 Taman Sidoarjo, Disertasi Doktor, UIN Sunan Ampel Surabaya.

Yazdi, M. (2012, May). E-learning Sebagai Media Pembelajaran Interaktif Berbasis Teknologi Informasi. In FORISTEK: Forum Teknik Elektro dan Teknologi Informasi, Vol. 2, No. 1.

\section{DOKUMENTASI KEGIATAN}

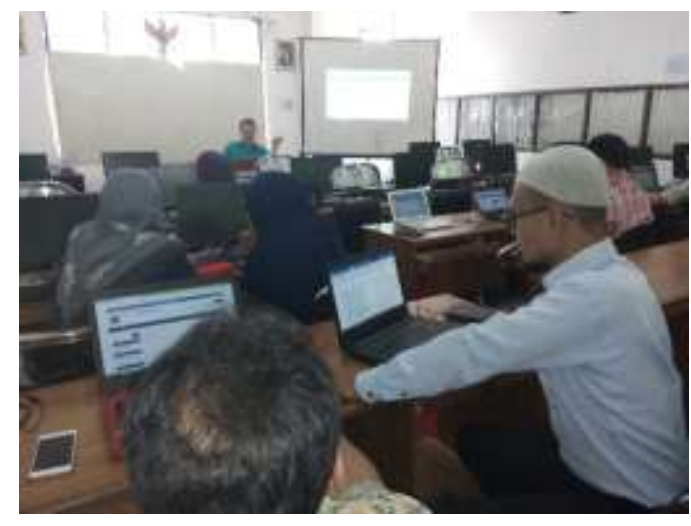

Peserta latihan menggunakan e-learning

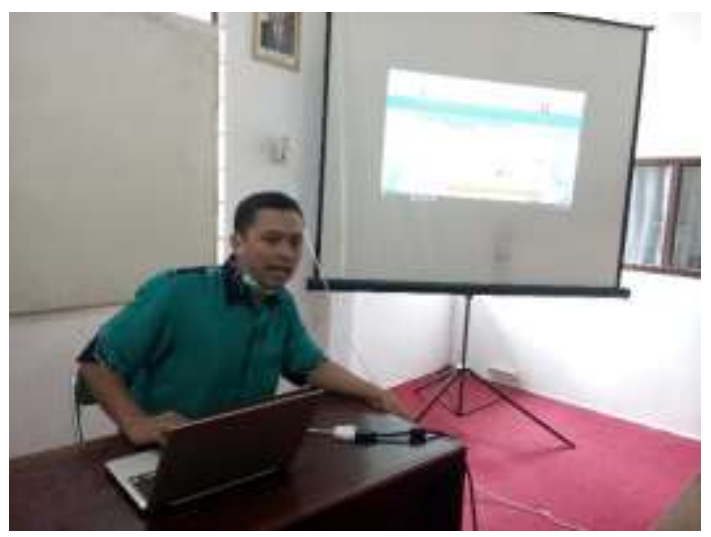

Instruktur mendemonstrasikan cara menggunakan e-learning

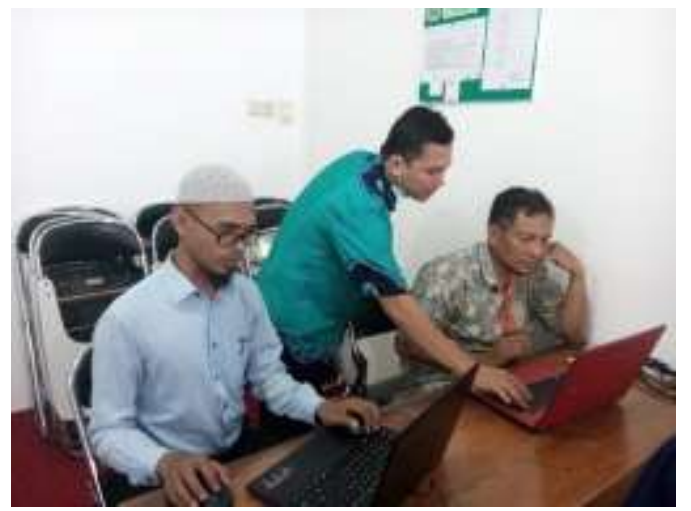

Instruktur membimbing peserta

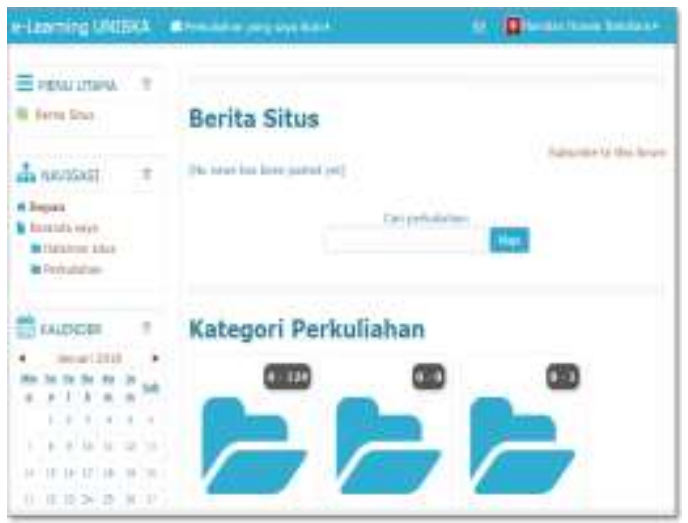

Halaman situs e-learning Uniska 